\title{
Assimilation Time As A Factor Of Performance: Impact On A New Generation Of Students
}

Lawrence C. Mohrweis, Northern Arizona University, USA

Kay C. Pitt, Northern Arizona University, USA

\begin{abstract}
This paper explores the issue of whether assimilation time has any bearing on the performance of students. Assimilation time is defined as the number of times during the week that a class meets. This study examined whether students would perform better in a 50-minute class that met three days a week versus a 75-minute class that met just two days a week. Assimilation time did make a difference (t-test, $p=.0693)$. High-attending students, that is students that attend class more that ninety percent of the time, performed better with more assimilation time that highattending students in sections with less assimilation time However, for "medium-attending" students there was no difference whether students attended class in a 50-minute class that met three days a week or a 75-minute class that met just two days a week.
\end{abstract}

\section{INTRODUCTION}

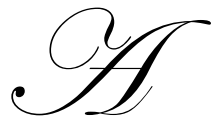

s educators we are now involved in teaching a new generation of students. These students have often been referred to as millennial students (Fogarty 2008, Milliron 2008). As stated by Fogarty, p. 369, "The generational category is upon educators with increased ferocity, since Millennials now make up the entirety of our traditional undergraduate student population." One attribute of millennial students is that they have been convinced, through supportive parenting, that they are "special" in every way. Another characteristic attributed to this group is that they seem to have much shorter attention spans.

This paper is a short note that explores the issue of whether assimilation time, which we define as the length of lectures and the number of times during the week that a lecture is given, would have any bearing on the performance of students. Specifically, we wanted to know whether students would perform better in a 50-minute class that met three days a week versus a 75-minute class that met just two days a week. Is the performance of millennial students impacted by the frequency of class meetings?

Class scheduling is a relevant issue for the college and learning curriculum. Faculty and administrators can often have dissimilar views on this topic. Many scholars seem to prefer two days a week schedules since such a teaching arrangement facilitates time to do research. Administrators, on the other hand, may view things differently. At our university, for example, an associate provost once offered his opinion that, "if we really cared about students" we should adjust our teaching schedules to offer fewer two days a week classes.

Previous studies have focused on whether condensed classes (e.g., summer classes) impact learning differently than traditional 15-week semester classes (Van Scyoc \& Gleason, 1993; Caskey, 1994; Scott; 1996). In finance, Henebry (1997) examined performances during the regular semester. She collected a decade's worth of data on course grades and non-passing grades in a junior-level finance course. Students in her study period had three scheduling options available to them; a once a week class ( 2 hours and 40 minutes), two day a week classes (75 minutes), and three day a week classes (50 minutes). She found no evidence that scheduling made any 
difference except with the once a week class. Students in a once a week class performed at a lower level. Going back to the eighties, Ward and Gowan (1989) found that they had a lower dropout rate from a management science statistics course that met on a three day a week schedule versus a two day a week schedule, but found no other significant factors between the two class-meeting categories. However, as Gaubatz (2003) reported, current research exploring the effect of class scheduling format changes on undergraduate student learning is quite limited. Our paper, on whether the frequency of class meetings impacts students' learning, is a study that should have broad appeal to educators.

\section{METHOD}

If the students of this new generation truly have shorter attention spans, then we would expect that classes with more assimilation time (i.e., a three days a week schedule) may facilitate learning by providing students with bursts of information in shorter segments. For example, when lectures are in 50-minute blocks of time and spread out over three days during the week, students would have greater opportunities to digest the material (i.e., review unclear material from the previous lecture, reread the book, or ask for additional help) before new material is introduced.

Student performance data was collected from a major southwest university from four sections of a Principles of Accounting - Managerial Course. Two classes met for fifty minutes on a Monday/Wednesday/Friday schedule while two other classes met only on a Monday/Wednesday schedule for seventy five minutes. Both classes were offered in the same semester, covered the same material, used the same textbook, and were taught by the same experienced lecturer. The only difference was that material was customized to fit the schedule taught: either three days a week (treatment) or a two days a week (control). In addition to the final scores for the students, we kept detailed records on the students' attendance during the semester.

Based on attendance, we group students into three categories: high, medium, and low attendees. Students were listed in the category of "high" if their class attendance over the semester showed that they attended class greater than ninety percent of the time. "Medium" students were those that attended class less than 90 percent of the time but at least 60 percent of the time. "Low" attendees were those students that attended class less than 60 percent of the time. Our hypothesis was that high attendees would perform better in classes with more assimilation time. The hypotheses, stated in the alternative form, are as follows:

$\mathbf{H}_{1}$ : $\quad$ Students that attend class frequently will perform better than students that attend class less frequently.

$\mathbf{H}_{2}$ : High-attending students in classes with more assimilation time will perform better than highattending students in classes with less assimilation time.

$\mathbf{H}_{3}$ : $\quad$ Medium and low-attending students in classes with more assimilation time will perform no differently than medium and low-attending students in classes with less assimilation time.

The first hypothesis was effectively a "no-brainer" experiment. As educators we are always telling our students that class attendance is important. It is part of our inherent belief system that students that attend class will perform better. The goal with the first hypothesis was to simply demonstrate that yes, it is true, attendance matters. In our study, the instructor gave no points for attendance. The second hypothesis, however, was the key focus of this study. We wanted to see if high-attending students would perform better in classes with more assimilation time.

With medium-attending students, we speculated that the impact of assimilation time would be minimal. For example, a "medium-attending" student is one that we classified as missing more than 10 percent of lectures which means that he or she, during a 15-week semester, has missed more than a week and a half of work. Such students would be forced to rely on informational sources, other than lectures, to understand the material. Therefore, we thought that because medium and low-attending students missed lectures so often the assimilation time would become irrelevant to their performance.

\section{RESULTS}


The subjects numbered 173 students, of which 77 students were enrolled in the two day a week class and 96 students were enrolled in the three day a week class. Table 1 shows the attendance of the three groups.

Table 1: Class Attendance Percentages

\begin{tabular}{|c|c|c|c|}
\hline Category & High & Medium & Low \\
\hline Attendance & Greater than $90 \%$ & 60 to $90 \%$ & Below $60 \%$ \\
\hline Students & $\mathrm{N}=81$ & $\mathrm{~N}=77$ & $\mathrm{~N}=14$ \\
\hline Mean Scores & 660.32 & 628.99 & 347.21 \\
\hline Standard Deviation & 74.91 & 88.53 & 130.96 \\
\hline T-Test on $\mathbf{H}_{\mathbf{1}}$ & \multicolumn{2}{|c|}{.0085} & \\
\hline
\end{tabular}

Students' attendance was categorized into three groups: high, medium, and low-attending. Students that attended class greater than ninety percent of the time were grouped into the high-attending category. There were 81 students in the high-attending group. The next category was labeled "medium-attending." We wanted a group size that was about the same size as our top group. Students attending class in the range of 60 to 90 percent were put into this group, resulting in a sample size of 77 students. The low-attending category was those students attending class less than 60 percent of the time.

Students could earn up to 800 points in the course. As shown in Table 1, high-attending students had a mean score of 660 points, whereas average students had a mean score of 629 points. In comparing high-attending versus medium-attending students, the first hypothesis $\left(\mathrm{H}_{1}\right)$ was statistically significant $(\mathrm{t}-\mathrm{test}, \mathrm{p}=.008)$. In other words, we found what we expected. Class attendance was a factor in students' performance.

Table 2 shows the results to test the hypothesis that high-attending students in classes with more assimilation time will perform better than high-attending students in classes with less assimilation time. There were 48 students in the three days a week class (treatment) and 35 students in the two days a week class (control). Table 2 shows that assimilation time did make a difference ( $\mathrm{t}$-test, $\mathrm{p}=.0693$ ). However, for "medium-attending" students, Table 3 shows that it made no difference whether students attended class in a 50-minute class that met three days a week or a 75-minute class that met just two days a week.

Table 2: High-Attending Students - Performance by Assimilation Time

\begin{tabular}{|c|c|c|}
\hline Class Meetings/ Weekly & Three 50-minutes classes & Two 75-minute classes \\
\hline Students & $\mathrm{N}=48$ & $\mathrm{~N}=35$ \\
\hline Mean Scores & 670.83 & 645.79 \\
\hline Standard Deviation & 66.06 & 84.53 \\
\hline \multicolumn{2}{|c|}{ T-Test on $\mathbf{H}_{2}$} & .0693 \\
\hline
\end{tabular}

Table 3: Medium-Attending Students - Performance by Assimilation Time

\begin{tabular}{|c|c|c|}
\hline Class Meetings/ Weekly & Three 50-minutes classes & Two 75-minute classes \\
\hline Students & $\mathrm{N}=43$ & $\mathrm{~N}=37$ \\
\hline Mean Scores & 630.02 & 627.78 \\
\hline Standard Deviation & 91.92 & 85.68 \\
\hline T-Test on $\mathbf{H}_{\mathbf{3}}$ & & .4560 \\
\hline
\end{tabular}

Finally, for low-attending students, seven students were from three days a week classes and seven from two days a week classes. Almost all of the students flunked the course (three students earned "D" grades in the course). The small sample size made it unrealistic to draw any accurate conclusions from this group with regard to three-days versus two days a week schedules.

\section{LIMITATIONS AND CONCLUSIONS}


We were fortunate to have a senior lecturer who taught four sections of the same class, during the same semester; two 50-minute classes on a Monday/Wednesday/Friday schedule and two 75-minute classes on a Monday/Wednesday schedule. The students in this study took the same exams, had the same homework requirements, and were taught by the same instructor. Conducting an assimilation study is a challenging undertaking since educators seldom have teaching schedules that would facilitate comparisons.

However, a limitation to this study is that the treatment classes, those on the three days a week schedule, were morning classes whereas the control classes, those on a two days a week schedule, were afternoon classes. It is possible that the lecturer may have been "worn out" by mid-afternoon which could have affected the quality of the teaching.

In conclusion, for millennial students who attended class on a regular basis, the frequency of class meetings made a difference in performance. For other millennial students, specifically those who did not attend class on a regular basis, the number of class meetings each week made no difference in performance.

The debate over assimilation time provides several issues for future research. For example, how does assimilation time impact on-line learning? The idea that learning would be facilitated by bursts of information in shorter segments appears to be consistent with the recent work of Holmen (2008). He reported that students in online courses felt that they had a richer learning environment when discussion questions were short and simulation activities were well defined. Another issue for future research is to examine the impact that assimilation time has on advanced accounting courses. For example, this study examined only the performance of students in a Principles of Accounting course. Would assimilation time continue to be a factor in the performance of students enrolled in Intermediate Accounting or Advanced Accounting classes? Also, what about accounting classes offered in the summer? Are we doing students a service by offering classes in a compressed time frame? Finally, as educators we often encourage students to attend class with the caveat that attending class is important for learning. This study clearly supports the assertion that students' class attendance is a positive factor in learning.

\section{AUTHOR INFORMATION}

Lawrence C. Mohrweis is a Professor of Accounting at The W. A. Franke College of Business at Northern Arizona University

Kay C. Pitt is a Senior Lecturer of Accounting at The W. A. Franke College of Business at Northern Arizona University

\section{REFERENCES}

1. Caskey, S. (1994). Learning outcomes in intensive courses. Journal of Continuing Higher Education (Volume 42): 23-27.

2. Fogarty, T. J. (2008). The millennial lie. Issues in Accounting Education (August): 369-371.

3. Henebry, K. (1997). The impact of class schedule on student performance in a financial management course. Journal of Education for Business (November/December): 114-120.

4. Holmen, J. (2008). Stimulating discussion in on-line graduate courses: Successes and failures. The Accounting Educators' Journal (Volume XVIII): 1-14.

5. Gaubatz, N. (2003). Course scheduling formats and their impact on student learning. The National Teaching \& Learning Forum (Volume 12, No. 1).

6. Milliron, V. C. (2008). Exploring millennial student values and societal trends: Accounting course selection preferences. Issues in Accounting Education (August): 405-419.

7. Scott, P. (1996). Attributes of high-quality intensive course learning experiences: Student voices and experiences. College Student Journal (Volume 30): 69-77. 
8. Ward, H., and J. Gowan. (1989). Statistics course retention associated with classes meeting different days of the week. College and University (Volume 64, No. 2): 199-207.

9. Van Scyoc, L. J., and J. Gleason. (1993). Traditional or intensive course lengths? A comparison of outcomes in economics learning. Journal of Economic Education (Winter): 15-22. 